\title{
Porque Hoje é dia de Maria, todos os dias são dias de Maria'
}

Marly C. B. Vidal

Mestra e doutora em Ciências da Comunicação pela Escola

de Comunicações e Artes da Universidade de São Paulo

E-mail:myc@uol.com.br

Jane A. Marques

Professora do Curso de Lazer e Turismo da Escola de Artes,

Ciências e Humanidades da Universidade de São Paulo;

mestra e doutoranda em Ciências da Comunicação pela Escola

de Comunicações e Artes da Universidade de São Paulo.

E-mail: janemarq@usp.br

Em seu texto seminal A cultura popular na Idade Média e no Renascimento: o contexto de François Rabelais, Mikhail Bakhtin, citando Michelet, afirma: "Rabelais recolheu sabedoria na corrente popular dos antigos dialetos, dos refrões, dos provérbios, das farsas dos estudantes, na boca dos simples e dos loucos"2, e aponta as fontes populares como sendo determinantes do "[...] conjunto de seu sistema de imagens bem como sua concepção artística”.

O popular como fator determinante das imagens e da concepção artística é que explicaria a resistência ao existente, ao estabelecido como regra, ao que já deu certo e, portanto, é garantido; a idéia de criação de imagens "[...] que se distinguem pelo caráter não-oficial" ${ }^{\prime \prime}$, é o que nos move na direção de Hoje é dia de Maria ${ }^{5}$, microssérie de Luís Alberto de Abreu e Luiz Fernando Carvalho, levada ao ar em janeiro de 2005, pela TV Globo.

Sob o ponto de vista da análise do discurso, visto como ato verbal e extraverbal, produto como processo inacabado, demandando novas e plurais possibilidades, pretendemos surpreender as especificidades do discurso, chegando à possível demarcação da complexidade, da criatividade, que consideramos não-oficial, oposto ao burocrático, solene e formal; ao tom popularesco, didático, consumista, atendendo à demanda de audiência, às solicitações fáceis de aceitação imediata.

Interessa-nos compreender como ocorre a produção de sentido, como o texto é produzido, apreendido e como se insere entre vários sistemas, cada um com seu discurso peculiar. Vislumbramos um enredamento, uma tessitura de várias e diferentes fibras e linhas que, tal como uma bordadeira, o autor fia,

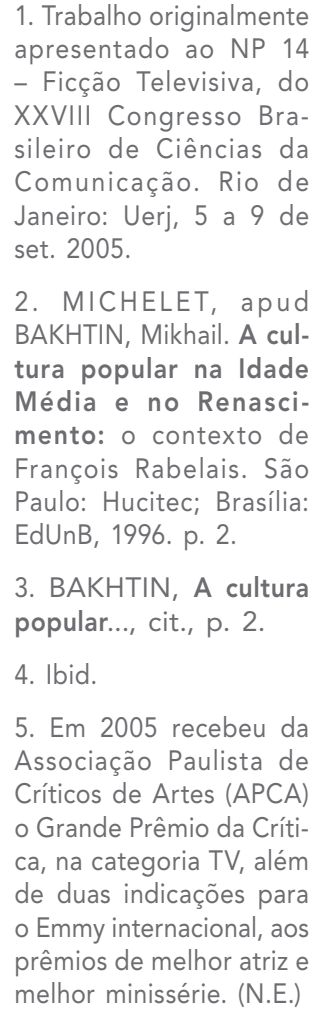

1. Trabalho originalmente apresentado ao NP 14 - Ficção Televisiva, do XXVIII Congresso Brasileiro de Ciências da Comunicação. Rio de Janeiro: Uerj, 5 a 9 de set. 2005.

2. MICHELET, apud BAKHTIN, Mikhail. A cultura popular na Idade Média e no Renascimento: o contexto de François Rabelais. São Paulo: Hucitec; Brasília: EdUnB, 1996. p. 2.

3. BAKHTIN, A cultura popular..., cit., p. 2.

4. Ibid.

5. Em 2005 recebeu da Associação Paulista de Críticos de Artes (APCA) o Grande Prêmio da Crítica, na categoria TV, além de duas indicações para o Emmy internacional, aos prêmios de melhor atriz e melhor minissérie. (N.E.) 
comunicação \& educação • Ano XII • Número 2 • maio/ago 2007

escolhe e tece de modo a permitir a emergência do significado e dos saberes humanos, dando assim ao conhecimento o homem em seus diferentes modos de ser.

\section{O ANTIGAMENTE QUE É ATUAL}

A televisão brasileira tem-se mostrado bastante hábil ao tematizar a realidade nacional. Autores e diretores de ficção televisiva não escondem a intenção de discutir, comentar essa realidade, seja ela contemporânea, seja histórica. Nota-se que a contemporaneidade vem sendo tratada especialmente em telenovelas que podemos chamar de originais, enquanto as adaptações versam melhor sobre fatos históricos.

Dentro de nossa abordagem teórica, o que propomos é a presença da realidade, quer histórica, quer contemporânea, sempre em interação, continuamente dialogando com outros textos; portanto, bebendo em fontes já existentes. Sugerimos que Hoje é dia de Maria constitui uma outra voz, a segunda, situada fora do discurso, que se consignou chamar de literatura popular que narra a nossa história, os nossos mitos e lendas, os causos, (re)apresentando o homem na rua, na praça, na cidade, no campo; vivendo, enfim. Apropriando-se do jogo dialógico desse material, a autoria recria, em um enredamento de linguagens, inclusive com a narração em off reforçando a oralidade, e nos entrega um produto televisivo, imagético em sua caracterização, mas não dispensando o lingüístico. Oferece um produto do gênero dramatúrgico, no formato microssérie em relações enunciativas com seu intertexto e seu contexto de produção e de consumo, em um lugar e um tempo, em condições sociohistóricas determinadas.

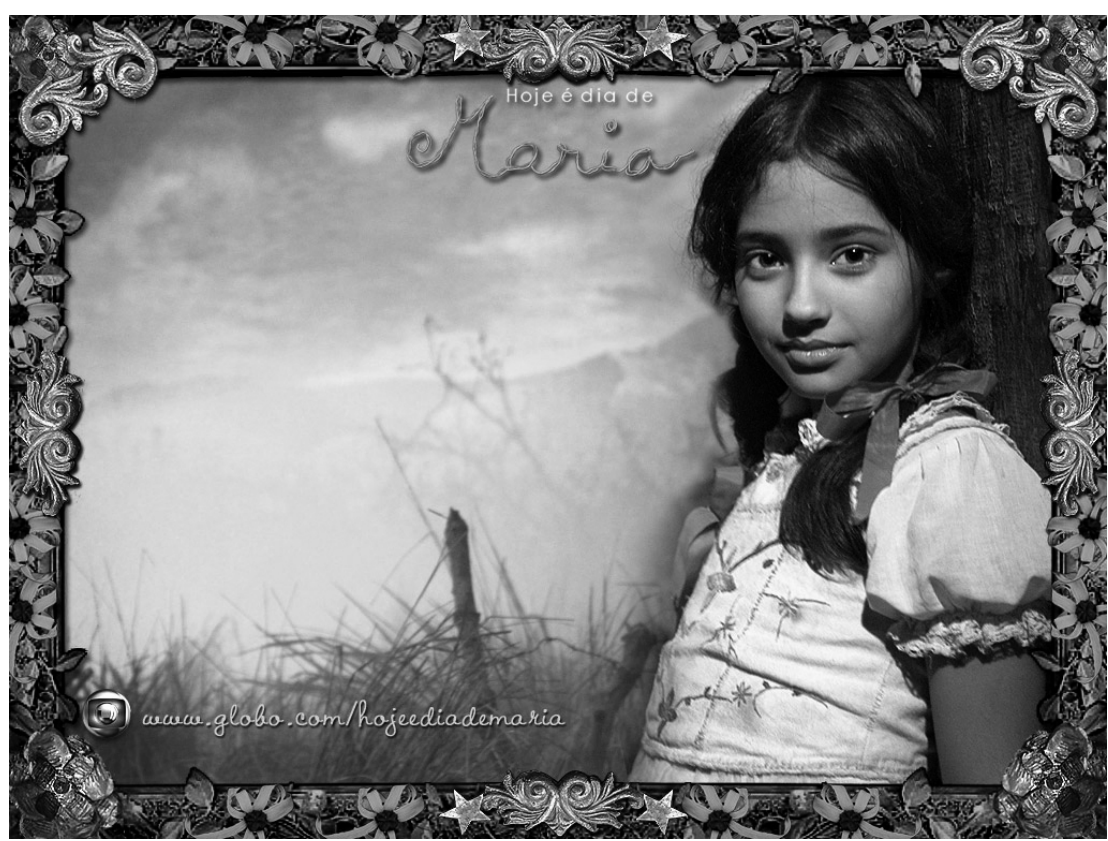




\section{AS FONTES POPULARES}

Caracterizar e definir cultura popular tem sido um trabalho hercúleo, e não cabe nos limites deste trabalho. Pensamos ser necessário algum balizamento a fim de não desbordarmos para campos mais complexos e/ou estranhos ao nosso objetivo e evitarmos uma concepção de popular estreita, presa a cânones congelados. A cultura popular apresenta infinitas formas, freqüentemente, de características libertas do convencionalismo oficial, da seriedade burguesa; é pouco radical e nada fundamentalista em suas relações com a religiosidade.

A cultura popular abriga mitos e lendas, ritos, espetáculos (antigas formas registradas pela cultura medieval - farsas, autos, momos, arremedilhos, milagres), obras verbais (a maioria anônima), muitas das quais não chegam à escrita. Abarca obras, de natureza diversa, nas quais a língua é mais vulgar, de utilização do povo no cotidiano e nas ruas, formas do vocabulário familiar, salpicadas de grosserias, insultos, juramentos. Essas formas populares verbais, de modo geral, traduzem temas populares, próprios de viventes que se acham longe do oficial, do bem-posto numa sociedade mais voltada para o ter. Oferecem uma visão de mundo, do homem e das relações humanas, em parte semelhante àquela detectada por Bakhtin na obra rabelesiana: um "[...] segundo mundo $\mathrm{e}$ uma segunda vida" ${ }^{\circ}$, paralela à oficial e à qual os homens da época pertenciam, ou melhor, "viviam" em determinadas ocasiões.

Ariano Suassuna, referindo-se à Cavalgada da Pedra do Reino, afirma ser a "Maior aula-espetáculo do mundo, pois a cidade inteira se transmuda em personagem de meu romance" . Vale destacar que a cavalgada é uma festa típica do sertão nordestino que comemora um fato relativo à comunidade - remete às festas realizadas nas praças dos burgos medievais. Bakhtin afirma sobre essas festas que são populares pela sua não-oficialidade, implicando participação do povo que fazia delas algo único: "Entendemos que a cidade suspende suas atividades e vive por uns poucos dias esse outro mundo que reputamos de natureza bakhtiniana". E nesse outro mundo, temos celebrações que remontam ao passado com seus temas coletivos, a voz, o improviso, o instante e o provisório sendo responsáveis por expressões em constante movimento que não ocultam empréstimos alheios e retomadas, sempre se renovando e retornando ao povo, sua origem, numa relação quase umbilical.

Olívio Tavares de Araújo afirma ser a arte popular aquela "[...] feita por artistas que permanecem sempre ligados a seus ambientes de origem, e que ela é basicamente consumida pelos próprios companheiros do artista, por sua comunidade, em seu meio social" ${ }^{\prime \prime}$.

A arte popular pode ter utilidade imediata no caso de cerâmica ou de tecelagem, de brinquedos e até de objetos feitos do reaproveitamento de produtos industriais com novas finalidades. Mas há objetos que enfeitam as casas da própria comunidade onde são produzidos e, hoje, por uma questão de modismo, chegam à casa dos ricos: figuras de barro, de papier-mâché, de madeira, de casca de árvore e de frutas, de sementes. São peças e figurinhas que apresentam com
6. BAKHTIN, op. cit., p. 5.

7. Ibid.

8. NOGUEIRA, Maria Aparecida Lopes. $\mathrm{O}$ cabreiro tresmalhado: Ariano Suassuna e a universalidade da cultura. São Paulo: Palas Athena, 2002. p. 33.

9. Grifo nosso.

10. ARAÚjO, Olívio Tavares. Arte popular em "A Peleja de Ana Maria Machado". Rio de Janeiro: Berlendis \& Vertechia, 1986. (Arte para criança: arte popular). 
grande fidelidade as pessoas, os bichos, os hábitos, as festividades que ocorrem em torno do artista. Mestre Vitalino nos legou em barro policromado $\mathrm{O} \mathrm{Pa}-$ lhaço, A Banda (Procissão da Zabumba), Noivos (Casamento a cavalo), figuras que nos mostram a vida no sertão.

Logo no início, a microssérie em foco nos apresenta a protagonista, Maria (Carolina de Oliveira), tentando sobreviver às agruras da vida. Nas suas andanças em busca das franjas do mar, ela encontra e reencontra arquétipos que retomam a ancestralidade, permitindo estimular a imaginação do expectador, conforme afirma Luiz Fernando Carvalho ${ }^{11}$.

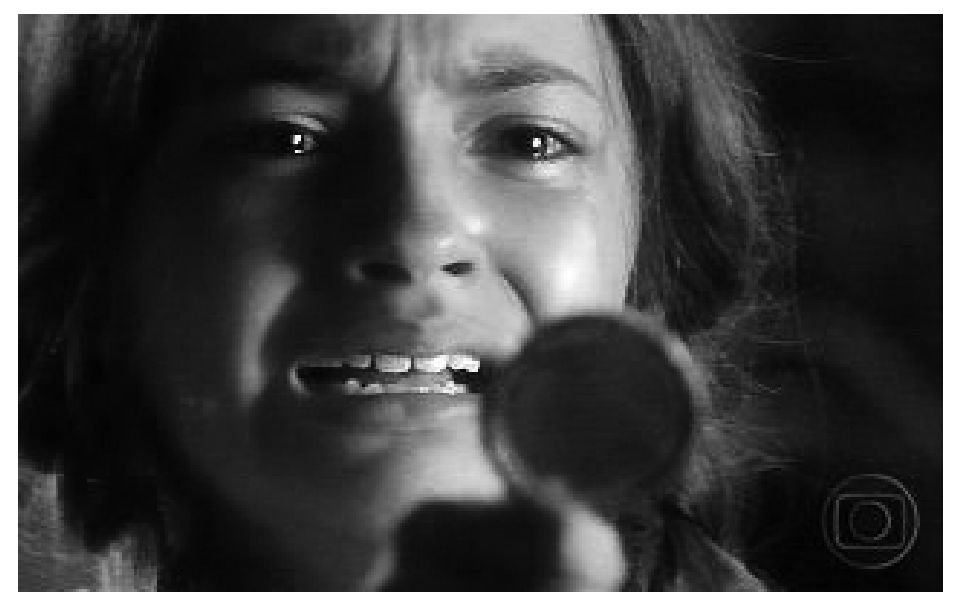

11. Disponível em: <http://redeglobo6. globo.com/Hojeediademaria>. Acesso em: 18 maio 2005.

12. Purunga. DICIO. NÁRIO Houaiss da Língua Portuguesa. Rio de Janeiro: Objetiva, 2001. p. 2264.

13. COELHO, Nelly Novaes. O conto de fadas. São Paulo: Ática, 1998.

O cantil que Maria carrega é uma purunga ${ }^{12}$ - escrita modificada de porongo, cabaça, fruto do cabaceiro amargoso em formato de "vaso de barro com gargalo estreito"- ajeitada para carregar água, ou seja, algo encontrado na natureza que é transformado pelas mãos do homem do povo em objeto de utilidade indispensável em suas andanças num ambiente ressequido.

No contexto de nosso trabalho, uma outra produção cultural importante surge: o conto de fadas. Especialistas no assunto ${ }^{13}$ fazem diferença entre conto de fada e conto maravilhoso. Interessa-nos aqui a redescoberta dos tempos inaugurais, a sedução do mítico e das origens arcaicas que se expressam sob a forma de fadas ou do maravilhoso. Entendemos o maravilhoso, o fantástico, o onírico não como uma mentira, uma fantasia inconseqüente, e sim como frinchas e brechas por onde nos espiam - e possíveis de serem capturadas - algumas de nossas verdades humanas.

No baú da falecida avó de uma das autoras deste artigo, foi encontrado um caderno; nele, uma história que seu pai leu quando ela era ainda menina:

Num reino distante, no tempo em que os animais falavam, num maravilhoso castelo, num cantinho de uma torre, uma princesinha chorava porque sua mãe tinha morrido. Branca-de-Neve agora tinha só pai. Passado um tempo - acho que de um ano -, o rei se casou novamente e trouxe para o palácio uma mulher que virou sua esposa e rainha do reino. A rainha tinha um espelho mágico. 
Enquanto isso a princesinha crescia e ficava uma mocinha muito bonita, uma lindeza. A madrasta - é assim que se chama a esposa do pai, que não é mãe da filha - ficou com ciúmes da princesinha... tinha muita inveja da beleza dela porque ela era muito branquinha e tinha olhos azuis. Então...

E por aí segue a história que todos nós conhecemos em diferentes versões. Eis uma mais recente:

Era uma vez uma rainha muito invejosa, que tinha um espelho mágico.

Todo dia ela perguntava:

- Espelho meu, existe alguém mais lindona do que eu?

Um dia ela olhou no espelho e viu uma cara de espuma bolorenta, com nariz de torneira, cabelos de pregos espetados e uma dentadura arreganhada caçoando dela. A rainha levou um susto e gritou:

- Guardas, prendam esse espelho! Mamãe, será que eu pareço uma lata enferrujada?!

O Gargalhão deu uma gargalhada e disse:

- Eu vou sumir e voltar, sua feiona!

[...]

O Gargalhão da direita (do espelho) perguntou:

- Onde está Branca-de-Neve?

- E eu vou saber? - respondeu a rainha. - Essas princesas de hoje saem sozinhas pela floresta e nem avisam a gente!

- É mentira! - gritou o Gargalhão da esquerda. - Você mandou o caçador matar a princesinha!

A rainha começou a chorar e o Gargalhão saiu correndo para pegar o caçador antes que ele alcançasse Branca-de-Neve e matasse a princesinha ${ }^{14}$.

As histórias se repetem marcadas pela oralidade. Em Hoje é dia de Maria, uma narradora (Laura Cardoso) entra vez ou outra para preparar e anunciar a cena a ser mostrada.

A essas formas verbais acrescentaríamos as produções plásticas, musicais, o circo, a dança, as festas, expressões que se espalham por esse Brasil de antanho, arcaico, que guarda, mesmo que em contato com tecnologias avançadas, uma visão de mundo, se não distante do oficial, coexistindo em paralelo, como um segundo, ou melhor, um outro.

Os saltimbancos aos quais Maria, agora adulta (Letícia Sabatella), se junta armam um palco, cuja boca de cena tem uma moldura que remete à Comedia del'arte, com pequenas esculturas de máscaras e objetos de cena. Há sempre um estandarte de pano grosso, com os fios evidentes e bordados coloridos, assim como as roupas do Palhaço, do tipo Arlequim. As vestimentas das personagens exibem o tecido, com panejamentos, debruns, enfeites. Detalhes que não aparecem apenas para ilustrar a narrativa, e sim para ser a narrativa, ou seja, fazer parte dela como elementos ativos na construção do discurso.

A abertura da microssérie mostra relação com o passado e o popular. As imagens apresentadas sinalizam o que está por vir, integram a música e a escrita, e são montadas de modo a sugerir uma atmosfera teatral. O segundo diretor do trabalho, Luis Alberto Abreu, é homem de teatro com experiência
14. Gargalhão-de-Neve e a Branca-Embolorada. Folha de S. Paulo. Folhinha, 6 jun. 1982. 
comunicação \& educação • Ano XII • Número 2 • maio/ago 2007

no trato com o palco. Talvez isso explique a cenarização construída dentro de uma bolha - o domo, que serviu de palco principal no Rock in Rio e foi transportado ao Projac para a execução da microssérie -, que congrega o espaço aberto necessário ao caminhar de Maria à idéia de permanência. Pelo seu formato, permitiu a realização de cenas em $360^{\circ}$ e planos de seqüência, além de melhores efeitos especiais e de luz para fotografia. Cria-se uma espécie de grande palco que não esconde, ao contrário, mostra, exibe a sua ficcionalidade. As pinceladas, traços e cores de Cândido Portinari estão ali representadas e são também elementos não só do cenário, mas da linguagem, ou seja, estruturais. A produção dialoga com o passado, estabelece formas de intertextualidade, quando integra expressões não-verbais como matéria-prima a ser recriada.

Carlos Alberto Sofredini, autor do texto que serviu de âncora para Carvalho e Abreu realizarem a microssérie, caracterizou-se por uma capacidade sui generis de diálogo com o passado. Em A carrera do Divino, sucesso teatral da década de 1970, ele vai mais longe e se apóia no texto de Antônio Cândido, Os parceiros do Rio Bonito, o primeiro estudo científico sobre as questões de linguagem caipira no interior de São Paulo. Em Hoje é dia de Maria, ele passeia pelo popular nacional que se encontra registrado em Câmara Cascudo e, mais longe ainda, em Silvio Romero.

A trilha musical, considerada elemento constitutivo de momentos vividos e ações praticadas pelas personagens, traz à cena o movimento sugerido pelas cirandas de Villa-Lobos e também uma marca de brasilidade, Pixinguinha, quando o chorinho Carinhoso explode na tela. Os repentes, os desafios, os jogos de linguagem, as cantigas de roda mostram a cara do País. Esses elementos não só fazem referência a nossa história como nação, mas se configuram como estrutura discursiva, legitimando a existência factual histórica. Como fazer-linguagem releva a ficção, mas é essa ficção que torna verossímeis fatos e personagens, transforma a realidade histórica de modo que o espectador possa experimentá-la.

\section{O DISCURSO MICROSSÉRIE}

Ao afirmarmos que nosso ponto de vista é o da análise do discurso e nosso caminhar se fará no campo da linguagem, tornam-se necessárias algumas explicitações de ordem teórica, especialmente porque estamos trabalhando não somente com a polissemia lingüística, mas com um produto cultural, que chamamos de discurso, genericamente falando dramatúrgico e em termos de

15. BRANDÃO, Helena Nagamine. Introdução à análise do discurso. Campinas, SP: UNICAMP, 1995. p. 89.

16. CLARK, Katerina; HOLQUIST, Michael. Mikhail Bakhtin. São Paulo: Perspectiva, 1998. p. 225 e 237. formato, microssérie, essencialmente, híbrido para usarmos o lugar-comum, em face do embricamento de várias linguagens e da constituição que reputamos ser de apropriação, recriação, reescrituração.

Discurso, segundo Nagamine, "[...] é efeito de sentido construído no processo de interlocução" ${ }^{15}$; recusa, portanto, à mera transmissão de informação, daí ser uma ação comunicativa, "[...] o discurso não reflete uma situação; ele é a situação" ${ }^{16}$. 
O homem tem o poder da elocução - expressão de idéias, sentimentos. Elocução é: interlocução: "[...] processo de interação entre indivíduos através da linguagem verbal ou não-verbal" ${ }^{\prime \prime}$, manifestada através da enunciação: conjunto de signos provenientes de indivíduos socialmente organizados, concreto, compreendendo o produto - material, verbal e visual em toda sua complexidade de linguagem televisiva - e o processo, a situação em interação orgânica.

Não sendo a enunciação somente aquilo que é dito, há um conjunto de fatores que vão suprir o não-dito, permitindo assim a significação. Há um texto realizado verbal, visual e um nexo que o liga à sua proferição, à sua mostração - a entonação -, entendida como apreciação avaliativa, um acento apreciativo que ao suprir o não-dito (categorias como posição social, grau de intimidade, relações afetivo-emocionais) o configura nos padrões das proferições. Ao trabalharmos imagem, podemos pensar nos padrões visuais, já que a entonação pode ser considerada em termos de como uma coisa é dita (televisão tem em seu fundamento o discurso oral e a palavra como matéria-prima), é mostrada, e que vai tornar evidente a simultaneidade do dito e do não-dito e tem efeitos evidentes sobre a linguagem - o que é dito, o que é mostrado.

O discurso artístico, para Bakhtin, é uma forma especial de comunicação social, não sendo autotélico, é menos implicado em seu ambiente de produção e de percepção. Não se nega ao discurso artístico, qualquer que seja sua natureza, a inserção no social ${ }^{18}$, no contexto e no intertexto. O discurso artístico é prenhe de linguagens socialmente diversificadas e artisticamente organizadas em que autores, narradores, personagens, gêneros os mais variados numa algaravia plural, múltipla, polissêmica, constituem significado na interação com o leitor, o espectador. "[...] O discurso nasce do diálogo com sua réplica viva, forma-se na mútua orientação do discurso de outrem no interior do objeto. A concepção que o discurso tem de seu objeto é dialógica." ${ }^{19} \mathrm{O}$ dialogismo é marca do homem, a alteridade seria a definidora de nossa humanidade, pois é impossível pensar o homem sem relacioná-lo com o outro. Em relação ao discurso, duas seriam as concepções bakhtinianas quanto ao dialogismo: entre interlocutores e entre discursos.

De tempos e culturas outros, emergem vozes e visagens que, cruzando-se no interior do discurso, o situam na história e exigem buscas semânticas, abordagens que permitam a compreensão e percepção das relações nesse novo e outro discurso Hoje é dia de Maria - um recontar e retomar das histórias populares. Temos um discurso que se apropria de outro(s), tecido de múltiplas vozes polemizando, que se completam ou respondem umas às outras, encontrando-se internamente no discurso, reproduzindo diálogos.

Quando, em seu labor criativo, Sofredini toma emprestado o popular nacional que se encontra registrado em Câmara Cascudo, em Silvio Romero, ele não escapa à lógica do processo: seu texto também não será jamais acabado, concluído, fechado. Permanecerá aberto a retomadas, a novas reescrituras. Quando Sofredini bebe nas fontes populares, o que ele está promovendo é um diálogo com essas fontes. Ao pinçar as histórias anônimas que circulam,
17. BAKHTIN, Mikhail. Marxismo e filosofia da linguagem. São Paulo: Hucitec, 1992. p. 113.

18. Vide MOTTER, Maria Lourdes. Ficção e realidade: a construção do cotidiano na telenovela. São Paulo: Alexa Cultural, 2003.

19. BAKHTIN, Mikhail. Questões de literatura e estética: teoria do romance. São Paulo: Unesp/Hucitec, 1993. p. 69. 
comunicação \& educação • Ano XII • Número 2 • maio/ago 2007

muitas delas orais, nesse mundéu do interior brasileiro e as inserir em suas obras, ele está dialogando com elas e trazendo à luz um novo discurso. Ora, quando Carvalho adapta para a televisão, ele está recriando, reescrevendo, tomando emprestado, apropriando-se de um modo de criação que é de Sofredini e fazendo um outro que é o seu, com sua entonação e para televisão. Outra linguagem daí nascerá, e essa nova linguagem sofre a inserção de outras próprias do veículo eletrônico e do formato que é a microssérie, dotada de linguagem diferenciada e peculiar.

Em relação ao dialogismo interno, isto é, entre interlocutores, a microssérie e a minissérie têm sido marcadas por inovadoras realizações. Programadas para irem ao ar esporadicamente, "de caráter festivo" ${ }^{20}$, usadas estrategicamente como marcadoras de datas importantes, contando com maiores recursos tecnológicos, mais tempo para sua feitura e sendo obra fechada, portanto menos sujeitas às agruras da audiência e, principalmente, pelo seu horário de exibição, ambas supõem um público sofisticado, mais exigente, pois detentor de maiores opções de lazer. Há micro e minisséries que têm encantado o grande público, colocando na telinha trabalhos requintados e ao mesmo tempo de grande penetração, com audiências surpreendentes como, por exemplo, O Auto da Compadecid ${ }^{21}$.

\section{MARCAS FANTÁSTICAS}

No seu ir-e-vir pelo sertão inóspito onde a noite nunca chega, Maria se vê presa nas minas de carvão, situação mostrada por Dickens em Oliver Twist ${ }^{22}$ e tão cotidiana também no Brasil, onde há crianças trabalhando pelo pão de cada dia e em condições degradantes. A fuga do casamento recupera a história de Cinderela, com direito a madrasta e sapatinho perdido ao bater das doze badaladas. Mas vestido e sapato não foram providenciados pela fada, e sim pelo mascate, figura comum na vida interiorana brasileira até recentemente.

Além das figuras populares, estão presentes personagens míticos, como o diabo Asmodeu (Stênio Garcia), que se multiplica em outros sete e está sempre em busca da sombra (entregar a alma ao diabo) das pessoas que encontra pelo caminho. Ele se opõe ao Pássaro, que se metamorfoseia em homem (Rodrigo Santoro), paixão de Maria adulta e que a protege nas suas andanças.

O fantástico se faz mesclado de personagens animados com inanima-

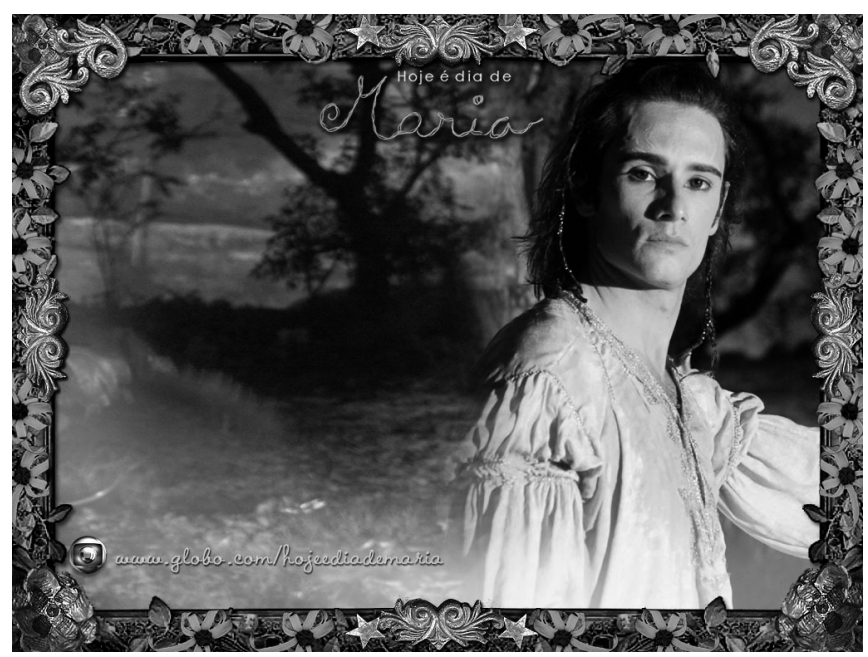


dos - homens como bonecos, bonecos representando animais. Arcaicos e contemporâneos. Os bonecos, figuras dos executivos modernos e urbanos que, como representantes das grandes corporações, chegam ao mais recôndito do sertão. Os retirantes, os índios e seus rituais, os cangaceiros sobreviventes do sertão, dentre outros personagens marcadamente populares, que, transportados de um tempo e espaço outros, se fazem atuais.

O popular também está nas festas de rua, na procissão de são João, no circo, nos saltimbancos, no parque de diversão. É o momento em que o homem se alça além do cotidiano e vive a festa, propõe uma inversão, um novo modo de vida que se distancia das lides comuns e obrigatórias da sobrevivência.

Os modos fantásticos têm um papel preponderante e não estão ali simplesmente para enfeitar a trama, o enredo, e sim como elementos condutores da narrativa: o apagar da vela, o amassar da flor que Maria cuidava, fazem-na desfalecer. Maria joga o coco para o alto e a noite chega - o coco, a palmeira, objetos da realidade, cujo valor tem a ver com a sobrevivência dos mais necessitados. A par disso há uma simbologia forte na ação de Maria: a noite que lhe foi roubada, e aos seus companheiros de sertão, representa o descanso, o sono, o refresco do sol inclemente. Os personagens que aparecem e desaparecem magicamente; a água jogada na terra que faz chover no sertão - rituais mágicos que remontam a nossa ancestralidade. Como nas narrativas orais, de berço popular, tudo cabe dentro do fantástico, pois de forma inesperada as coisas acontecem e revelam o inusitado e muitas vezes o desejado. Essas ações não são de inventividade recente. Estão lá na grande temporalidade, num tempo e num momento em que a pouca ou nenhuma ciência impossibilitava explicações e os mitos e lendas se faziam elucidações.

\section{CONSIDERAÇÕES FINAIS}

O que se nos dá à miragem logo na primeira cena? É o sertão? Talvez o de Guimarães Rosa: "O sertão é do tamanho do mundo" ${ }^{23}$. Nesse emaranhado de galhos, troncos, pedras, pó, secura, um dia cairá a neve. É onde Maria se move, se (re)move, e esse espaço-cenário indefinido é fantástico. É cenário que se mostra como tal, não-natural, e sim inventado, ficcional, quer ser e é criado. Releva a ficção, é a realidade de Maria, mas é propositalmente falso. Temos um discurso que constrói a representação da situação enunciativa; o cenário não é um quadro para se inserir nele uma enunciação, e sim um espaço legitimado pela própria enunciação, pelo texto, por aquilo que nele se desenrola.

É tomando emprestado do teatro a encenação; mas uma encenação que, tecnologicamente falando, ocorre numa bolha construída em estúdio (o domo) para dar a impressão de um caminhar que é ao mesmo tempo circular, como se Maria, caminhando sempre, encontrando-se com o amigo, com o diabo e com outras personagens, não saísse do espaço/tempo. Quando a narrativa passa
23. ROSA, João Guimarães. Rosiana. Rio de Janeiro: Salamandra, 1983. p. 16. Edição especial comemorativa dos 75 anos do autor, para MPM Propaganda, exemplar 4669/11000. 
para o convencionalmente chamado segunda parte, o tempo avança, mas o espaço como que se mantém.

Não importa se a história foi um sonho, pois a própria Maria exclama: "Parece que foi sonho!"; não importa se de fato aconteceu e reverteu (Maria menina em adulta, Maria adulta em menina), afinal, o que é de verdade? Mariazinha também trazia esses questionamentos: "E o amor, quando é de verdade? E a felicidade, quando é de verdade?" ${ }^{24}$.

A promessa de novos dias de Maria, como já anunciado pela emissora, promete que essa história não há por que acabar por aqui. Como as histórias populares, há sempre quem conte outra(s).

Resumo: A partir da microssérie Hoje é dia de Maria, resgata-se a tecedura das histórias populares, entremeadas de fantástico e recriadas a partir da oralidade - primeira característica da narrativa. A partir da teoria bakhtiniana, busca-se compreender a trama e o resgate dialógico entre a cultura popular e a trama ficcional televisiva. Essa estrutura dialógica está presente na linguagem verbal (marcada pela oralidade) e não-verbal (cenários, figurinos, bonecos articulados, marcadamente mostrados como tais), além dos personagens animados e inanimados que completam o encadeamento dos fatos e episódios relatados.

Palavras-chave: ficção televisiva, microssérie, cultura popular, fantástico, apropriação.
Abstract: Looking into the microserie Hoje é dia de Maria it is possible to rescue the composition of popular stories, mixed with the fantastic and recreated from oral language - a primary characteristic of narrative. Using the Bakhtinian theory we try to understand the plot and the dialogical talk between popular culture and fictional television warp. The dialogical structure can be identified in the verbal (pointed by orality) and non-verbal language (identified as sceneries, costumes, and articulated dolls) and animated and unanimated characters that complete the chaining of narrated facts and episodes.

Keywords: televise fiction, microserie, popular culture, fantastic and appropriation.
24. ABREU, Luis Alberto de; CARVALHO, Luiz Fernando. Hoje é dia de Maria: roteiros da 1 a $\mathrm{e}$ 2a jornadas. São Paulo: Globo, 2005. p. 346 